\section{Trans-ciliary minimally invasive keyhole craniotomy for skull base and vascular lesions}

Sir,

Conventional approaches to the anterior and lateral skull base would necessarily include a large craniotomy and possibly an orbitozygomatic osteotomy. ${ }^{[1,2]}$ Approach-related complications include visible scars, increased blood loss during surgery, facial and orbital ecchymosis, and long-term problems such as temporalis muscle atrophy and painful jaw opening. ${ }^{[2]}$ Many skull base lesions can be easily accessed via a minimally invasive keyhole craniotomy using an eyebrow incision. This approach is effective in minimizing surgical trauma, hospital stay, and long-term morbidity. ${ }^{[3,4]}$

We reviewed the records of all patients operated via the supra-brow approach over the past 5 years in our center. A total of 29 patients had been operated via this approach. Their ages ranged between 1 and 64 years; there were 19 adults and 10 children; 17 patients were males. Fifteen patients were operated for aneurysms and 14 patients for other lesions [Table 1].

All except one giant cavernous segment aneurysm presented with subarachnoid hemorrhage. All patients were operated in the early postrupture period ( $<5$ days); the subarachnoid space was thus filled with dense clots in all instances [Figure 1]. We did not, however, have to use lumbar cerebrospinal fluid drainage in any of the cases. Intraoperative rupture occurred in 2 cases; the bleeding could be controlled by rapid temporary clipping of the parent vessel in both instances. In the tumor group, gross total excision could be achieved in 12 of the 14 patients [Figure 2]. In 2 patients with craniopharyngioma, tumor residue was left due to dense

Table 1: Details of the various lesions operated and the surgical outcomes

\begin{tabular}{lcl}
\hline Lesion & Number & Outcome \\
\hline Aneurysms & 15 & \\
Locations & 12 & All clipped completely \\
$\quad$ ACom & 2 & with parent and distal \\
ICA bifurcation & 1 & vessel preservation \\
$\quad$ Cavernous ICA & 9 & Complete excision in 7 \\
Craniopharyngioma & 2 & Complete excision \\
Pituitary adenoma & 2 & Complete excision \\
Tuberculum sellae meningioma & 1 & Complete excision \\
Orbital hydatid cyst & &
\end{tabular}

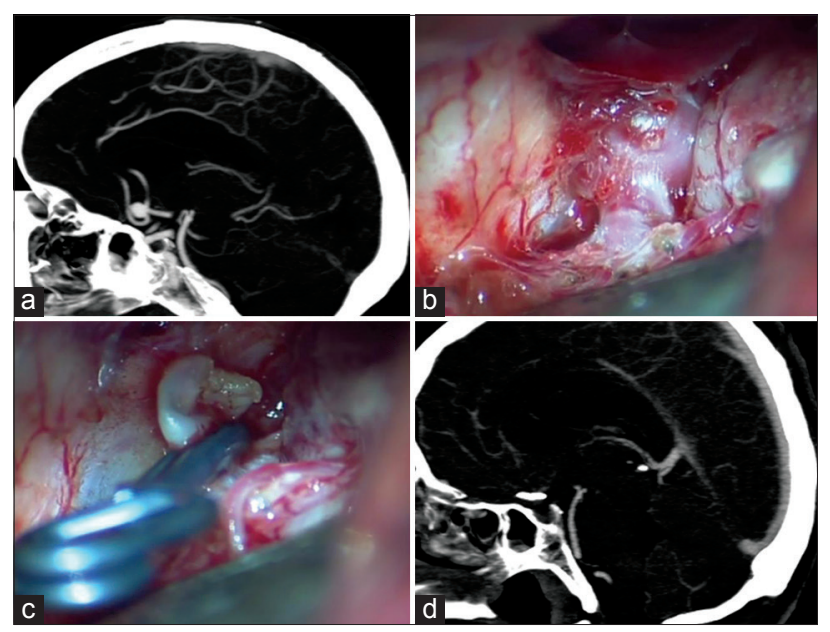

Figure 1: An ACom artery aneurysm. (a) The preoperative computed tomography (CT) angiogram (sagittal view) showing the aneurysm fundus projecting anteriorly. (b) Intra-operative view of the aneurysm. (c) Clip applied across the neck. (d) Postoperative CT angiogram showing no residual fundus 
adhesions to the optic chiasm and hypothalamus. Both these patients received imaging-guided radiotherapy subsequently.

\section{Table 2: Complications in this series}

\begin{tabular}{lc}
\hline Complication & Incidence (\%) \\
\hline Intraoperative rupture & $2(13.3)$ \\
Subtotal tumor excision & $2(22.2)$ \\
Periorbital ecchymosis & $6(20.7)$ \\
Death (due to ventriculitis) & $1(3.4)$ \\
\hline
\end{tabular}
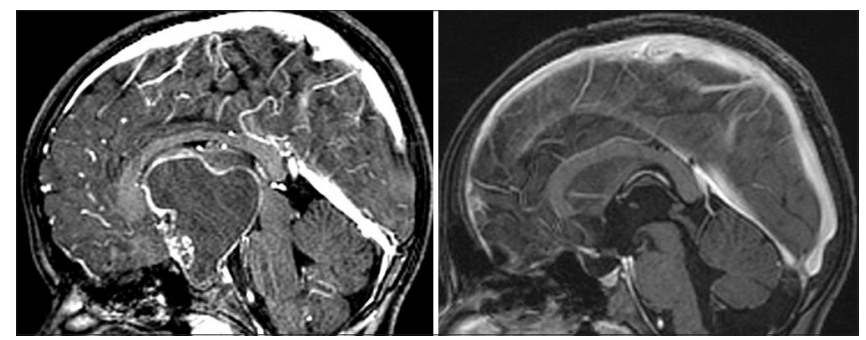

Figure 2: Preoperative and postoperative images of a giant craniopharyngioma excised via the mini-frontal supra-brow craniotomy

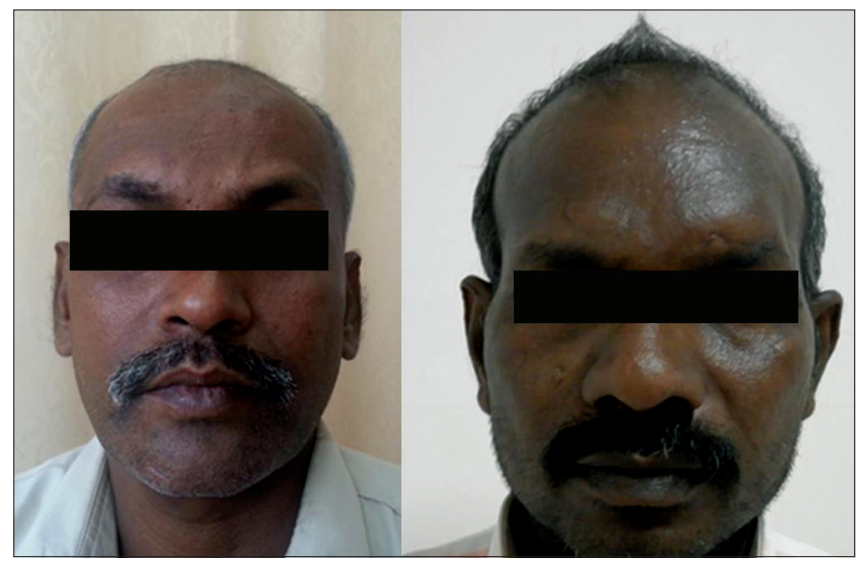

Figure 3: Patients with partial baldness. The conventional pterional incision would have left a disfiguring scar. The supra-brow incision is barely visible.

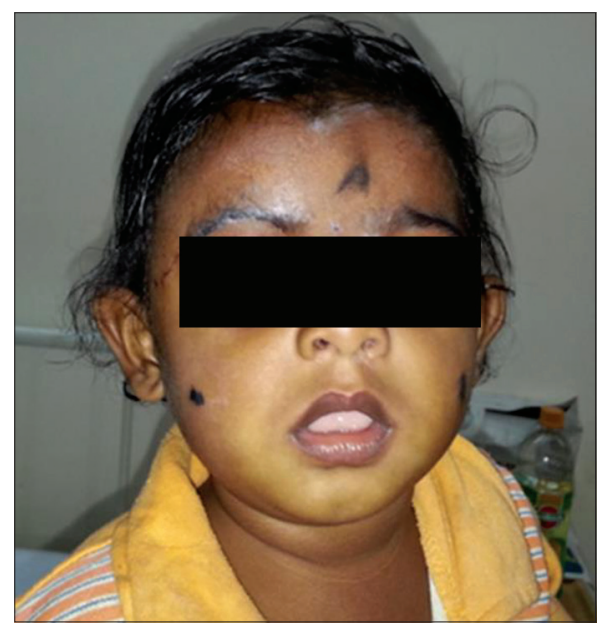

Figure 4: A 1-year-old child operated for craniopharyngioma; the incision has healed well
The duration of the surgical procedures varied between 1.5 and $3.5 \mathrm{~h}(1 \mathrm{~h}<$ the conventional procedures at our center). The average blood loss was $<250 \mathrm{ml}$ and none of the patients received a blood transfusion.

All patients tolerated the procedure well and required analgesics for a maximum of 5 days. None of them had any difficulties in chewing or swallowing. Six patients had periorbital ecchymosis which resolved in 5-7 days [Table 2]. The scar of the operative incision was inconspicuous at 6 weeks follow-up. Four patients in this group had a receding hairline with partial baldness, and the cosmetic outcome was especially good in them [Figure 3]. The wound healed well in children as well, and there was no loss of hair on the eyebrow [Figure 4].

The application of keyhole approaches depends on an exact knowledge of neuroanatomy. The introduction of long bayonetted instruments has made minimal access surgery safe. ${ }^{[3,4]}$ There is a definite learning curve to implement these approaches. ${ }^{[5]}$ The addition of an endoscope can provide a "third eye," permitting the surgeon to peer into blind crevices not visualized through the microscope.

The mini-frontal keyhole craniotomy via a supra-brow incision should become a standard part of a neurosurgeon's armamentarium to tackle skull base lesions.

\section{R. Roopesh Kumar, Venkatesh S. Madhugiri, A. S. Ramesh, Awdesh K. Yadav}

Department of Neurosurgery, Jawaharlal Institute of Postgraduate Medical Education and Research, Gorimedu, Pondicherry, India

Address for correspondence: Dr. V. R. Roopesh Kumar, Professor of Neurosurgery and Senior Consultant Neurosurgeon, SRM Institute for Medical Sciences (SIMS), 1, JN Road, Vadapalani, Chennai - 600027 . India. E-mail: roops1975@gmail.com

\section{Declaration of patient consent}

The authors certify that they have obtained all appropriate patient consent forms. In the form the patient(s) has/have given his/her/their consent for his/her/their images and other clinical information to be reported in the journal. The patients understand that their names and initials will not be published and due efforts will be made to conceal their identity, but anonymity cannot be guaranteed.

\section{References}

1. Yasargil MG, Fox JL. The microsurgical approach to intracranial aneurysms. Surg Neurol 1975;3:7-14.

2. Day JD. Surgical approaches to suprasellar and parasellar tumors. 
Neurosurg Clin N Am 2003;14:109-22.

3. van Lindert E, Perneczky A, Fries G, Pierangeli E. The supraorbital keyhole approach to supratentorial aneurysms: Concept and technique. Surg Neurol 1998;49:481-9.

4. Hernesniemi J, Ishii K, Niemelä M, Smrcka M, Kivipelto L, Fujiki M, et al. Lateral supraorbital approach as an alternative to the classical pterional approach. Acta Neurochir Suppl 2005;94:17-21.

5. Lan Q, Gong Z, Kang D, Zhang H, Qian Z, Chen J, et al. Microsurgical experience with keyhole operations on intracranial aneurysms. Surg Neurol 2006;66 Suppl 1:S2-9.

\begin{tabular}{|l|l|}
\hline \multicolumn{2}{|c|}{ Access this article online } \\
\hline Quick Response Code: & Website: \\
\hline & www.ruralneuropractice.com \\
\cline { 2 - 2 } & \\
\hline
\end{tabular}

